\title{
Cuidar permanência: enfermagem 24 horas, nossa maneira de cuidar
}

\author{
Permanent care: 24 hours nursing care, our way to take care \\ Atencíon permanente: enfermería en las 24 horas, nuestra manera de cuidar
}

\section{Angelina Monteiro Furtado', Viviane Peixoto dos Santos Pennafort', Lúcia de Fátima da Silva', Lia Carneiro Silveira', Maria Célia de Freitas', Maria Veraci Oliveira Queiroz' \\ 'Universidade Estadual do Ceará. Mestrado Acadêmico em Cuidados Clínicos. Fortaleza, CE}

Submissão: 03/06/2009

Aprovação: 09/07/2010

\section{RESUMO}

Estudo teórico-reflexivo, instigado pela epistemologia de Gaston Bachelard e pelo projeto "Mil e Uma Maneiras de Cuidar na Enfermagem" de Maria José Coelho. Teve como objetivo delinear novas maneiras de cuidar na enfermagem dialítica, tecendo um sistema de cuidados dispensados ao paciente renal crônico. Foram descritos sete cuidados de enfermagem que permeiam cuidar de pessoas em tratamento dialítico: acolhimento, vínculo, técnicas especializadas, estímulo ao autocuidado, avaliação do tratamento, enfrentamento da rotina desestimulante e resgate à cidadania. Emergiu o cuidar permanência, compreendido como uma relação articulada e complementar entre o saber científico presente no cuidado de enfermagem e a valorização da essência do outro, como ser complexo em sua integralidade. Descritores: Diálise renal; Filosofia em enfermagem; Cuidados de enfermagem.

\section{ABSTRACT}

Theoretical-reflexive study motivated by the epistemology of Gaston Bachelard and by the project "Thousand and one ways to take care in Nursing" by Maria José Coelho. We had as objective to trace new ways to take care in dialysis nursing, creating a system of cares offered to chronic kidney patients. Seven nursing cares that involve care of people in dialysis treatment were described: reception; bonding; specialized techniques; support to self-care; assessment of the treatment, facing the unstimulating routine; and citizenship rescue. Permanent care emerged, understood as an articulate and complementary relation between the scientific knowledge present in nursing care and the valorization of the other's essence, as a complex being in its whole.

Key words: Renal dialysis; Philosophy, nursing; Nursing care.

\section{RESUMEN}

Estudio teórico y reflexivo basado en la epistolología de Gaston Bachelard y por el proyecto "Mil y Una Maneras de Cuidar Específicas de la Enfermería” de Maria José Coelho. Tuvo como objetivo delinear nuevas maneras de cuidar en la enfermería dialítica, construyendo un sistema de atención necesário al paciente renal crônico. Hubo la descripción de siete cuidados de enfermería Que basaron la atención de personas: acojimiento, palpe, técnicas especializadas, estímulo al autocuidado, evaluación del tratamiento, enfretarse la rutina desestimulante y resgate a la ciudadanía. Surgió la atención permanencia, relación articulada y complmentar entre el saber científico presente en la atención de enfermería y la avalorazión de la esencia del otro, como ser complejo en su integralidad.

Descriptores: Diálisis Renal; Filosofía en enfermería; Atención de enfermería. 


\section{INTRODUÇÃO}

Esta reflexão, nascida das discussões da disciplina O Cuidado em Si, do Curso de Mestrado Acadêmico em Cuidados Clínicos (CMACCLIS), acerca da análise do conceito Cuidado em Enfermagem, reportou as pesquisadoras à prévia discussão produzida em outra disciplina do mesmo curso: Filosofia da Ciência. Nesta, utilizou-se a epistemologia de Gaston Bachelard, Que remete o homem diurno à reflexão de sua História, fazendo-o reconstruíla sempre, criando um interesse vital pelo instinto formativo e não conservativo do espírito científico, aliando-se a isso, o homem noturno, um ser poético, fenomenológico, em permanente busca de sua essência, sua subjetividade(l).

Houve também a contribuição de outros autores e teóricos, permitida pela sempre flexível proposta de construção dialética de saberes entre saberes, defendida por Bachelard. E, nesta dialética de saberes, tem-se Coelho ${ }^{(2)}$, autora do artigo Maneiras de Cuidar, Que incentivou a criar novas maneiras de cuidar, dando continuidade ao projeto Mil e Uma Maneiras de Cuidar Específicas da Enfermagem.

Portanto, a partir da ideia metafórica do "homem 24 horas" de Bachelard e do convite de Maria José Coelho, encontrou-se o fio Que teceu uma nova maneira de cuidar, delineada harmonicamente entre aspectos subjetivos e objetivos do ser humano, contextualizando esse cuidar, no exercício cotidiano do cuidado de enfermagem ao paciente renal crônico em tratamento de diálise. A essa maneira de cuidar denominou-se de Cuidar Permanência, da Qual emergiram as seguintes Questões norteadoras deste estudo: Qual a subjetividade e objetividade Que permeia a maneira de cuidar de pessoas Que precisam cotidianamente da terapia dialítica? Qual a intenção do cuidado da Enfermagem na terapia dialítica?

Para iniciar o cuidar permanência ao paciente, é preciso começar pelo momento do diagnóstico, Quando o paciente inicia o tratamento dialítico, recebendo de imediato o difícil diagnóstico de Insuficiência Renal Crônica (IRC). Um paciente inseguro, Que anseia saber Quem e como será recebido nesta nova realidade Que, aliás, é repleta de mudanças das mais diversas ordens, na Qual teoricamente não se tem alta hospitalar, pois dependerá desse tratamento para o resto de sua vida.

Os pacientes e seus familiares enfrentam diante da descoberta da doença renal crônica e das intervenções terapêuticas, situações desoladoras, por vezes incompreensíveis e inaceitáveis, de profunda transformação multidimensional, Que consiste em cuidados especiais por toda a vida. Dessa forma, o enfermeiro deverá está preparado para o cuidar permanência, por meio de condutas de aproximação, consideração e compreensão da existência do outro.

Com o reconhecimento da subjetividade/objetividade no cuidar da enfermagem, torna-se relevante buscar ações/decisões, agregando ao habitual modelo biologista a subjetividade que também permeia o cuidado em enfermagem, evidenciando nesta reflexão a rotina de trabalho do profissional enfermeiro dentro de uma unidade de diálise.

Diante do exposto, o estudo objetivou delinear novas maneiras de cuidar na enfermagem dialítica, tecendo um sistema de cuidados dispensados ao paciente renal crônico.

\section{REFERENCIAL TÉORICO-METODOLÓGICO}

Para descrever os cuidados da enfermagem prestados ao paciente com insuficiência renal crônica, optou-se por um estudo teóricoreflexivo na abordagem Qualitativa. Foram utilizados os conceitos de cuidar de Maria José Coelho ${ }^{(2)}$ e do conhecimento científico, segundo o filósofo Gaston Bachelard em sua obra denominada $A$ formação do espírito científico: contribuição para uma psicanálise do conhecimento e A poética do devaneio ${ }^{(1,3)}$.

O pensamento é dinamizado através de dois caminhos: o da epistemologia e o da poética, logo há a contestação de pressupostos e o afastamento de hábitos e atitudes de conhecimentos arraigados pela tradição. De um lado a ciência, com sua racionalidade e rigor, de outro, o devaneio, ou seja a subjetividade humana, Que nos enleva através de imagens súbitas e originais ${ }^{(1)}$. Ciência e poética, antagônicas como o dia e a noite, mas ao mesmo tempo, complementares, pois nos instauram num mundo novo surreal, elevando-nos enquanto homem em toda sua plenitude, pois é transitando nos dois caminhos Que se alcança a formação integral(4).

\section{RESULTADOS E DISCUSSÃO}

A seguir o delineamento do Cuidar Permanência, no Qual serão destacadas as sete maneiras de cuidar do outro, dispostas na sequência que ocorrem, ou seja, obedecendo à dinâmica regida pelo cotidiano da terapia dialítica (Quadro 1).

\section{$O$ primeiro cuidado}

O "cuidar admissional" apresenta-se como um conjunto de normas e rotinas, direitos e deveres. O paciente fragiliza-se Quando é hospitalizado, por está distante de seu habitat comum, a hospitalização faz com Que ele necessite se engajar em um outro grupo social. Ao dar entrada no hospital, o cliente sente que seu mundo ruiu. Recebê-lo bem, com atitude cortez e amigável é a articulação dos conhecimentos das ciências do comportamento para cuidar Que consolida este cuidar na enfermagem ${ }^{(2)}$.

O primeiro cuidado é sem dúvida o acolhimento ao paciente. Neste acolhimento, tem-se a postura receptiva assumida pelo profissional, exacerbando a humanização do seu atendimento, a sua atitude ao recebê-lo, escutá-lo, construindo uma relação de mútuo interesse ${ }^{(5)}$.

Contudo, dado o pressuposto de Que a pessoa deve tomar decisões, dar sentido e direção a sua vida, lutando e se esforçando para viver, apresenta-se como embasamento deste primeiro cuidado a Teoria Humanística de Josephine Paterson e Loretta Zderad, já Que esta busca compreender as vivências, considerando a singularidade do paciente enquanto ser único, com o seu próprio mundo vivido. Deste modo, o enfermeiro deve compreender a enfermagem como "uma experiência vivida entre seres humanos" autênticos. Neste tipo de interação "o significado da enfermagem como um ato humano é o ato em si mesmo", cuja enfermagem é compreendida como "uma resposta à situação humana"(6). Considerando essa dimensão de comunicação, a Enfermagem é entendida como um diálogo vivo, desenvolvida a partir da formação de uma relação intersubjetiva, entre um indivíduo único (EU) com o outro também único (TU). Nesta teoria, esta relação dialógica é facilitada por tais elementos, como: o encontro, o relacionamento, a presença, o chamado e a resposta ${ }^{(6)}$.

O paciente, ao receber o diagnóstico de IRC, sente-se inseguro, confuso, com muitas dúvidas porQue ainda não compreende a 


\begin{tabular}{|c|}
\hline PRIMEIRO CUIDADO \\
\hline Caracterizado pelo "acolhimento" \\
\hline Envolve a "comunicação" \\
\hline O paciente necessita da "escuta" \\
\hline SEGUNDO CUIDADO \\
\hline Caracterizado pelo "estabelecimento do vínculo intersubejtivo" \\
\hline Envolve o "estigma do corpo transformado" \\
\hline O paciente necessita "falar" \\
\hline TERCEIRO CUIDADO \\
\hline Caracterizado pela "tecnologia" \\
\hline Envolve a "técnica" \\
\hline O paciente necessita "enfrentar" \\
\hline QUARTO CUIDADO \\
\hline Caracterizado pelo "autocuidado" \\
\hline Envolve a "adesão" \\
\hline O paciente necessita de "apoio" \\
\hline QUINTO CUIDADO \\
\hline Caracterizado pela "avaliação" \\
\hline Envolve o "retorno" \\
\hline O paciente necessita de "possibilidades" \\
\hline SEXTO CUIDADO \\
\hline Caracterizado pela "rotina" \\
\hline Envolve a "sobrecarga" \\
\hline O paciente necessita da "compreensão da equipe" \\
\hline SÉTIMO CUIDADO \\
\hline Caracterizado pelo "reencontro com a cidadania" \\
\hline Envolve a "possibilidade de mudança" \\
\hline O paciente necessita de "resgate da autonomia" \\
\hline
\end{tabular}

\section{Quadro 1. Dimensões do cuidar permanência.}

amplitude de mudanças Que são inerentes a este diagnóstico. Acolher este ser, neste momento é acolher empaticamente a sua dor, a sua angústia e o seu medo(7).

Através da experiência das pesquisadoras deste estudo, percebeu-se Que no momento da revelação do diagnóstico, o paciente Quer ESCUTAR o profissional. Ele necessita da ESCUTA não porQue o enfermeiro sistematicamente tem Que informar o Que a ele vai acontecer, mas porQue deseja conhecer este novo mundo ao Qual acaba de adentrar. Esta percepção reflete o ENCONTRO entre o profissional (EU) e o seu paciente (TU), na medida em Que suas expectativas de FALA e de ESCUTA, respectivamente, são percebidas entre ambos. Os aspectos subjetivos são percebidos e a singularidade do ser posta à sua valorização.

A fala de um e a escuta do outro são vivenciadas em simultaneidade vivida: "é somente no relacionamento do NÓS que posso vivenciar concretamente você num determinado momento de sua vida"(8). O chamado e a resposta acontecem de forma verbal e não-verbal, cuja comunicação se estabelece com a fala do enfermeiro e a escuta curiosa do paciente. No momento em Que se reportou ao paciente com todas as informações, assumiu-se uma postura de respeito, dando-lhe liberdade de opções Quanto à terapêutica a ser seguida. Assim, adentrou-se em seu espaço íntimo, refletindo a confiança estabelecida.

O paciente, desta forma, passará então para uma próxima etapa Que rege o tratamento dialítico. A etapa das concretizações das mudanças inerentes à terapêutica. Com conhecimento recebido e a confiança no profissional Que dele cuida. Ele agora necessita falar sobre essas mudanças.

\section{O segundo cuidado}

O segundo cuidado será caracterizado pelo estabelecimento do vínculo intersubjetivo iniciado no primeiro cuidado, pois somente se chega ao significado subjetivo a partir das palavras que o outro fala ${ }^{(8)}$. Portanto, o paciente necessita falar sobre o tratamento Que irá iniciar e a esse assunto é inerente à mudança Que o seu corpo sofre.

Antes da mudança dietética ou da restrição hídrica, a instalação do acesso vascular para a hemodiálise ou o cateter abdominal para a diálise peritoneal é a primeira mudança pelo Qual o paciente passará. A imagem corporal é afetada pelo início do tratamento dialítico e o sofrimento é perceptível nesta etapa da terapêutica. Sentimentos de dor, devido às punções venosas, vergonha, medo, raiva, tristeza, constrangimento, fragilidade, angústia, mal-estar, frustração e indiferença são comuns nesses pacientes ${ }^{(9,10,11)}$.

Uma relação dialógica fortemente estabelecida deve ser evidenciada neste momento do cuidado, pois o paciente sente-se seguro à abertura do diálogo, renunciando ao desejo da escuta. Ele agora deseja FALAR, porque tem vontade de partilhar suas angústias, seus medos. $\mathrm{O}$ vínculo criado e agora estabelecido entre profissional e paciente permite a renuncia ao distanciamento entre ambos, transformando-os em parceiros de confiança.

Portanto, a instalação do acesso dialítico anuncia o próximo passo a ser dado. Um passo Que permeia a objetividade puramente tecnicista inerente ao início da sessão dialítica. Contudo, um profissional contaminado pelo vínculo estabelecido e sem esQuecer a subjetividade repleta de existencialismo-relacional, antecipa o seu cuidado e fortalece a sua parceria, ajudando o paciente no enfrentamento da árdua tarefa de iniciar o tratamento dialítico propriamente dito.

\section{O terceiro cuidado}

O paciente nesse momento defronta-se com a tecnologia Que o cerca. Uma tecnologia dura, permeada por maQuinários e ações técnicas repetitivas. O paciente, então, defronta-se com ela e necessita enfrentá-la.

Consiste no momento do "Cuidar dos Líquidos Corporais", líquidos que entram e que saem do corpo. É preciso medir, controlar, observar, anotar, comparar e acompanhar com precisão no momento em Que se fizer necessário. Os líquidos Que entram e saem e assim (des)equilibram o organismo(2).

Uma técnica realizada com a Qualidade regida pelo seu manual de padronização, pela segurança e habilidade do profissional e pela confiança estabelecida com o vínculo intersubjetivo remete ao paciente uma sensação de bem-estar, refletida pelo "entregar" de sua vida nas mãos de profissionais.

A punção de uma fístula, o manuseio de um cateter, a conexão do paciente a máquina de hemodiálise, a primeira vez do paciente sozinho em casa ao iniciar a diálise peritoneal não pode ser reduzido ao simplificado da ação livre e dissociada ao ato de cuidar. 
Um valor em si opõe-se à circulação de outros valores ${ }^{(3)}$. Então, Que valor é atribuído à técnica de enfermagem?

As técnicas e as tecnologias de enfermagem devem constituir o saber de enfermagem, valorizando-o, na medida em Que são utilizadas como recurso para o desenvolvimento do cuidado ${ }^{(12)}$. A objetividade da técnica de Enfermagem nas situações descritas deve estar imbricada na finalidade a Que as mesmas se prestam, ou seja, na necessidade subjetiva de cuidado daquele paciente.

O paciente, agora, contextualizado se integra à rotina crônica de seu tratamento e também à possibilidade de nele se acomodar. Contudo, vale lembrar de Que as necessidades humanas não apresentam inércia, por mais rotineiras Que se apresentem. E, o profissional tem Que estar atento a este fato, oferecendo ao paciente a chance de o mesmo vir a ser o ator principal de seu regime terapêutico.

\section{O Quarto cuidado}

Estando agora o paciente já integrado ao contexto de seu tratamento, ele necessita de APOIO para desenvolver o seu autocuidado por meio da adesão à terapêutica.

Neste cuidado, cite-se o método de ajuda APOIO, no qual o paciente poderá ser ajudado pelo sistema de apoio-educação. Nele o paciente conseguirá exercer o seu autocuidado, aprendendo com o enfermeiro a ser agente do mesmo ${ }^{(13)}$.

A adesão implícita nesta fase é extremamente importante para o seguimento ou não do autocuidado. A educação desse paciente Quanto ao cuidado com seu acesso vascular, seguimento da dieta ou até mesmo na realização do procedimento dialítico domiciliar será fator determinante para o sucesso desse cuidado.

É no âmago do próprio ato de conhecer Que aparecem os conflitos, nos Quais o pensamento empírico torna-se claro Quando os argumentos são estabelecidos. $\mathrm{O}$ ato de conhecer dá-se contra um conhecimento anterior, destruindo conhecimentos mal estabelecidos ${ }^{(3)}$.

O profissional, neste momento, cuida ao apresentar ao seu paciente à técnica de troca de bolsa em diálise peritoneal, desmistificando a ideia anterior de que aquele procedimento somente poderia ser realizado por alguém "letrado", cuida ao sensibilizá-lo Quanto à manutenção do curativo do cateter de hemodiálise para a prevenção de infecção, cuida ao orientá-lo sobre a fisiologia de funcionamento de sua fístula artério-venosa, alcançando os cuidados para evitar a sua perda, cuida ao ajudá-lo a enfrentar o seu medo de punção, cuida ao convidá-lo a participar de sua terapêutica, cuida ao convidá-lo a resgatar o controle de sua vida, de seu autocuidado.

"Diante do mistério do real, a alma não pode, por decreto, tornar-se ingênua. É impossível anular, de um só golpe, todos os conhecimentos habituais. Diante do real, aquilo que cremos saber com clareza ofusca o Que deveríamos saber"(3).

Dessa forma, o reconhecimento dos saberes do paciente e suas possibilidades frente ao autocuidado, à adequação em relação ao tratamento e às possíveis mudanças dentro de uma realidade Quase imutável, reflete a capacidade perceptiva do profissional ao valorizar o paciente além de sua condição biológica.

\section{O Quinto cuidado}

Neste momento, será realizada uma análise do processo de cuidar do paciente diante dos resultados apresentados, cujo retorno será permeado pela interação entre enfermeiro e paciente. Esse reencontro busca observar os resultados e discutir mediante as diversas formas de comunicação, como está acontecendo o cuidado institucional e domiciliar. Ou seja, juntos, profissional e paciente, estão conseguindo sucesso na terapêutica dialítica? Quais as deficiências e possibilidades encontradas?

Tentando compreender a relação entre o Que se apresenta explícito e o que se pretende como resposta ao cuidado prestado, tem-se Que o agir humano está em função de motivações focalizadas a objetivos, Que se projetam para um futuro, compreendidas como "motivo a fim de", já as razões para as suas ações estão conectadas em experiências do passado, denominadas de "motivos por que" desses atos ${ }^{(3)}$. Assim, o cuidar em enfermagem não pode ignorar o sentir-se humano expressado pelo paciente, nem o sentido Que atribui às próprias ações de cuidado, suas reações e experiências vividas.

Ainda, em busca da compreensão desses resultados, vale ressaltar Que os critérios usados como instrumentos de avaliação e verificação de um resultado são próprios do positivismo ${ }^{(3)}$, Que reduz a condição de intersubjetividade entre o cuidador e paciente. Então, percebe-se Que este ato de avaliar deve superar as Quantificações e generalidades, permitindo uma renovação científica, Que se processa pela "certeza da incerteza". "A verdade só ganha seu pleno sentido ao fim de uma polêmica. Não poderia haver assim verdade primeira. Só há erros primeiros”(3).

Logo, a avaliação compreensiva acontecerá Quando o enfermeiro permite uma parceria, e junto ao paciente e familiar, consegue encontrar possibilidades de melhora, com relação ao cuidado de enfermagem, ao autocuidado e à Qualidade de vida.

Esta avaliação precisa acontecer continuamente, para Que se consiga priorizar as necessidades do paciente frente ao tratamento dialítico, já Que no decorrer deste, o paciente vivenciará uma realidade repetitiva e por vezes desestimulante, como será verificado no sexto cuidado, caracterizado pela rotina.

\section{O sexto cuidado}

Ao abordar a insuficiência renal crônica na vivência das pesquisadoras, depara-se com uma condição de difícil enfrentamento tanto para o paciente, assim como para sua família. Envolve a rotina do tratamento dialítico, Que cansa, isola, causa ansiedade, desestimula, transforma o corpo e a mente.

Os pacientes nefropatas em início de tratamento dialítico geralmente sentem-se esperançosos, contudo, ao passar algum tempo, apresentam sentimentos ambíguos, pois começam a sentirse amedrontados pela morte. E, então, utilizam-se de mecanismos de defesa, como a negação, refutando a dependência da diálise, não seguindo às orientações e, na maioria das vezes, perdendo sua auto-estima ${ }^{(14)}$.

Além disso, a condição crônica é expressa pelas características de permanência, irreversibilidade, incapacidade residual, incurável, degenerativa e de longa duraçãa ${ }^{(15)}$. Diante deste cenário conflitante, surgem momentos de completa desesperança e abandono do autocuidado com os acessos para diálise e, pior, consigo mesmo.

Agora, é importante que o enfermeiro e toda equipe não imponham formas de cuidar, de tratar, mas busquem compreensão interdisciplinar do Que está acontecendo com esta pessoa. Ao explanar sobre a necessidade de compreensão como um meio para interpretação do sentido dado ao cuidado de enfermagem, remete o profissional a "revelar o Que se encobre na mera aparência", 
sendo necessário "alcançar o sentido, mostrando sua essência"(16).

É muito importante penetrar na estrutura dessa compreensão do outro, o suficiente para ver Que apenas se interpretam experiências pertencentes a outras pessoas, em termos de experiências que são de fato vivenciadas pelos profissionais enfermeiros, pois o relacionamento do NÓS básico já é dado pelo mero fato de que se nasce no mundo da realidade social diretamente vivenciada ${ }^{(3)}$. Partindo desse encontro, a compreensão do outro é alcançada Quando as opiniões prévias com as Quais se inicia uma relação não são arbitrárias ${ }^{(17)}$.

Nesse sentido, estar inserido em um tratamento dialítico, explicita a condição normativa Que é imposta ao paciente, na Qual requer adaptações e mudanças diversas com relação aos hábitos de vida, organização familiar e relações sociais. Assim, o enfermeiro junto à equipe interdisciplinar, precisa apresentar possibilidades ao paciente e seus familiares para o resgate da autonomia e melhor adesão ao tratamento dialítico. Essa necessidade de emancipação será explorada no sétimo cuidado, Que é caracterizado pela busca da cidadania.

\section{O sétimo cuidado}

Diante da necessidade de enfrentamento das adversidades da doença renal crônica, o resgate da autonomia visando à cidadania e à proteção dos direitos, envolve a participação ativa do paciente e de seus familiares em busca de seus valores, autoestima e reinserção social. Para exercer essa cidadania Que proporciona a autorrealização esta ação pode ser desenvolvida em Qual@uer momento e ambiente do cotidiano, entretanto, é necessário Que as pessoas permitam Que isso aconteça. A autorrealização das pessoas gera uma harmoniosa relação interpessoal e um clima de autoconfiança ${ }^{(12)}$.

Essa perspectiva de mudança consiste em redimensionar o cuidado como possibilidade ética da humanidade, sugerindo um dinamismo dialético em Que a relação de dependência acontece mais para construir autonomia dos atores envolvidos Que para se manter em si mesmo, como exercício autocentrado de poder. O cuidado como gestão da ajuda-poder tem como núcleo a dinamicidade tanto dos processos históricos, Quanto da natureza, assumindo-se aQui uma abordagem social, ecológica e epistemológica do cuidar ${ }^{(18)}$.

Compreendendo este caminhar pela cidadania como uma politicidade do cuidado, e esta se expressa pelo conhecer para cuidar melhor, ou seja, é a percepção e aceitação da dimensão existencial do outro; já o cuidar para confrontar, cuidar para emancipar propõese a libertar o cuidado de sua institucionalização capitalista predadória. Essa emancipação é o empoderamento da própria autonomia enQuanto pessoa, mas, além disso, esse fortalecimento do poder de decisão será capaz de estabelecer estratégias de enfrentamento e de autocuidar-se física, social e emocionalmente $e^{(18)}$.

Dessa forma, o paciente será capaz de se libertar dessa relação de submissão e passividade institucional, para então incorporar, em sua condição de adoecimento a possibilidade criativa e segura de sua existência como autor de sua própria saúde.

A classificação e descrições não são exaustivas, necessitam continuidade mediante contínua observação do cotidiano no sentido de completar as mil e uma maneiras de cuidar especificas da enfermagem ${ }^{(2)}$.

\section{CONSIDERAÇÕES FINAIS}

O fato de sobreviver com a insuficiência renal crônica, às vezes por longos períodos, não significa "viver bem", pois Quase sempre há limitações com prejuízos da participação em várias atividades cotidianas. Por isso, é importante abordar junto ao paciente o cuidado, mesmo em uma situação de cronicidade, "ser crônico", é preciso estimulá-lo à compreensão do "estar crônico", para emergir uma visão saudável em relação à continuidade da vida, não permanecendo na estagnação e passividade da doença.

Os principais obstáculos epistemológicos identificados no contexto da terapia dialítica foram: o conhecimento científico da equipe de saúde e a tecnologia, vistos como categóricos, rotina desestimulante, e a desvalorização da subjetividade humana.

O Cuidar Permanência, nesta perspectiva, pode ser entendido como: uma ação intencional de cuidar, construída a partir da interação entre os saberes científicos da enfermagem e a valorização da subjetividade humana. Considerando a relevância desse cuidar de enfermagem no cotidiano do paciente renal crônico e na superação dos obstáculos epistemológicos, propõe-se a construção do Cuidar Permanência, apresentado em uma seeuência de sete cuidados, julgados indispensáveis no atendimento às expectativas do paciente renal crônico. Um cuidar ante uma situação de cronicidade, permeada de ações técnicas repetitivas, contudo necessariamente imbricadas por pretéritas ações humanas, como a escuta, o acolhimento, o toque e a interação interpessoal.

Os cuidados elencados foram o acolhimento e vínculo efetivo com o paciente que está chegando, via de regra, para ficar. Após essa interação, o enfermeiro precisa desenvolver suas atividades técnicas com Qualidade e segurança, com base em um conhecimento científico aprofundado na área. Contudo, é preciso ir além da técnica instucionalizada e buscar junto ao paciente e familiar, meios para o autocuidado, já Que a continuação do cuidar acontecerá no domicílio. Com o retorno, Que configura uma rotina desestimulante, será possível avaliar o tratamento, suas deficiências, assim como, as possibilidades de mudança no resgate à cidadania. Não obstante, esses cuidados, embora sequenciados, não acontecem de forma linear, já Que são interdependentes.

Nessa perspectiva, de reconstrução de um saber e pela busca da superação dos obstáculos epistemológicos, ou seja, dos obstáculos biologicistas, sugere-se o cuidar permanência como uma relação articulada e complementar entre o saber científico, presente no cuidado de enfermagem, e a valorização da essência do outro, como ser complexo em sua integralidade.

\section{REFERÊNCIAS}

1. Bachelard G. A poética do devaneio. 2a ed. São Paulo: Martins Fortes; 2006.

2. Bachelard G. A formação do espírito científico: contribuição para uma psicanálise do conhecimento. I I ed. Rio de Janeiro:
Contraponto; 1996.

3. Coelho MJ. Maneiras de cuidar em enfermagem. Rev Bras Enferm 2006; 56(6): 745-51.

4. Barbosa E, Bulcão M. Bachelard: Pedagogia da razão, pedagogia 
da imaginação. Petrópolis: Vozes; 2004.

5. Silva Junior AG, Mascarenhas, MTM. Avaliação da atenção básica em saúde sob a ótica da integralidade : aspectos conceituais e metodológicos. In: Pinheiro R, Mattos RA. Cuidado: as fronteiras da integralidade. Rio de laneiro: CEPESC/ UERJ; 2006. p.24l-58.

6. Paterson JG, Zederad LT. Humanistic nursing. New York: National League for Nursing; 1988.

7. Queiroz MVO, Dantas MCQ, Ramos IC, Jorge MSB. Tecnologia do cuidado ao paciente renal crônico: enfoque educativoterapêutico a partir das necessidades dos sujeitos. Texto Contexto Enferm 2008; 17(1): 55-63.

8. Shutz A. Fenomenologia del mundo social: el mundo de la realidad social directamente vivenciada. Buenos Aires: Editorial Paidos; 1972. p.192-201.

9. Koepe GBO, Araújo STC. A percepção do cliente em hemodiálise frente à fístula artério-venosa em seu corpo. Acta Paul Enferm 2008; 2 I (esp): 147-5 I.

10. Furtado AM. Fístula artério-venosa: sua importância para os pacientes em tratamento de hemodiálise [monografia]. Fortaleza: Departamento de Enfermagem, Universidade Estadual do Ceará; 2002.

11. Cruz DOA, Araújo STC. Diálise peritoneal: a percepção tátil do cliente na convivência com o cateter. Acta Paul Enferm 2008; 21 (esp): 147-5 I.

12. Nietsche EA. Tecnologia emancipatória: possibilidade para a práxis de enfermagem. Ijuí: Unijuí; 2000.

13. Foster PC, Janssens NP. Dorothea E. Orem. In: George, JB. Teorias de enfermagem: os fundamentos para a prática profissional. Porto Alegre: Artes Médicas; 1993.

14. Meireles VC, Goes HLF, Dias TA. Vivências do paciente renal crônico em tratamento hemodialítico: subsídios para o profissional enfermeiro. Ciênc Cuid Saúde. 2004; 3(2): 169-78.

15. Freitas MC, Mendes MMR. Condição crônica: análise do conceito no contexto da saúde do adulto. Rev Latino-am Enfermagem 2007; 15(4): 590-97.

16. Silva LF, Damasceno MMC, Carvalho CML, Souza PDS. Cuidado de enfermagem : o sentido para enfermeiros e pacientes. Rev Bras Enferm 200I; 54(4): 578-88.

17. Minayo MCS. O desafio do conhecimento. Pesquisa Qualitativa em saúde. 1 I $^{\text {a }}$ ed. São Paulo: Hucitec; 2008.

18. Pires MRGM. Politicidade do cuidado como referência emancipatória para a enfermagem: conhecer para cuidar melhor, cuidar para confrontar, cuidar para emancipar. Rev Latino-Am Enfermagem 2005; 13(5): 729-36. 